\title{
Experimental and theoretical study of the effect of hull roughness on ship resistance
}

\author{
Soonseok Song, Saishuai Dai, Yigit Kemal Demirel, Mehmet Atlar, Sandy Day, Osman Turan
}

Department of Naval Architecture, Ocean and Marine Engineering, University of Strathclyde, 100 Montrose Street, Glasgow G4 0LZ

\begin{abstract}
Hull roughness increases ship frictional resistance and thus results in economic and environmental penalties. Its effect has been prevalently predicted using the similarity law scaling procedure, presented by Granville (1958; 1978). However, this method has not yet been validated with experimental data using a model ship.

This paper presents an experimental investigation into the effect of roughness on ship resistance and provides a validation of the similarity law scaling, by using tank testing of a flat plate and a model ship. Both the plate and the ship were tested in smooth and rough surface conditions, respectively. For the rough surface conditions, sand grit (aluminium oxide abrasive powder) was applied on the surfaces of the flat plate and the ship model. The roughness functions of the rough surface were derived by using the results obtained from the flat plate tests. Using the roughness function and the flat plate towing test, the frictional resistance was extrapolated to the length of the model ship following the similarity law scaling procedure. The total resistance of the rough ship model was first predicted using the extrapolated frictional resistance and the result of the smooth ship model, and then compared with the results from the rough ship model. The predicted total resistance coefficients for the rough ship model showed good agreement with the measured total resistance coefficient of the rough ship model; thus proving the validity of using Granville's similarity law scaling to extrapolate the roughness effect on ship resistance.
\end{abstract}

Keywords: Roughness effect; model ship towing test; Granville's similarity law scaling; ship resistance; experimental fluid dynamics (EFD)

\section{Introduction}

Roughness of a ship's hull, which is often caused by hull fouling (Townsin, 2003) and corrosion (Tezdogan and Demirel, 2014), can dramatically increase the ship resistance and hence its fuel consumption and greenhouse gas emissions, as well as the cost associated with drydocking (Schultz et al., 2011). Accordingly, there have been numerous investigations into the roughness effect on ship resistance from the earliest times to the present (e.g. McEntee, 1915; Hiraga, 1934; Kempf, 1937; Benson et al., 1938; Watanabe et al., 1969; Loeb et al., 1984; Lewkowicz and Das, 1986; Lewthwaite et al., 1985; Haslbeck and Bohlander, 1992; Schultz, 1998; Schultz and Swain, 1999; Schultz, 2002; Schultz, 2004; Shapiro, 2004; Andrewartha et al., 2010; Schultz et al., 2011; Demirel, 2015; Demirel et al., 2017a ; Li et al., 2018; Demirel et al., 2019).

Although the adverse effects of surface roughness on skin friction have been well acknowledged since the early days, extrapolating the lab-scale experimental data to full-scale ship resistance is not an easy task due to the unique feature of the roughness effect in scaling. That is, the size of the surface roughness cannot be scaled up or down (Franzini, 1997).

The boundary layer similarity law analysis, which was proposed by Granville (1958; 1978), can be used to extrapolate the roughness effect of skin friction. The merit of using this method is that once the roughness function, $\Delta U^{+}$, of the surface is known, the full-scale roughness effect on an arbitrary length of the body with the same roughness can be predicted. Since there is no universal roughness function for all types of roughness, the roughness functions for individual roughness types have to be obtained using either a direct method or an indirect method. The indirect methods, presented by Granville $(1958 ; 1987)$, have been preferred by researchers to the direct methods, since the indirect methods are generally simpler and more convenient as they are more readily attainable and require a less expensive investment, whereas the direct method involves the measurement of the boundary layer profiles, which requires more accessible channels and costly set-up systems, or water-unfriendly hot-wire anemometry facilities (Atlar et al., 2018). 
Accordingly, there have been a large number of experimental studies to acquire the roughness functions and the corresponding roughness Reynolds number, $k^{+}$, using the indirect methods, including local method with displacement thickness (Schultz and Swain, 1999; Flack et al., 2005), local method without displacement thickness (Karlsson, 1978), overall method using towed plates (Schultz and Myers, 2003; Schultz, 2004; Shapiro, 2004; Demirel, 2015; Demirel et al. 2017a), rotating disk method (Schultz and Myers, 2003; Holm et al., 2004), or pressure drop method using fully turbulent flow channels (Schultz et al., 2015; Li et al., 2019). Schultz and Myers (2003) further concluded that the roughness functions obtained from the different indirect methods can bring a good agreement with the results obtained by using the direct method.

Although Granville's similarity law scaling was derived based on reasonable assumptions and shows a good agreement with full-scale ship trial results (Schultz, 2007), Granville's similarity law analysis is still limited by the assumptions of flat plate, uniform distribution of roughness Reynolds number and the roughness function (Demirel et al., 2017b).

Recently, there have been studies using Computational Fluid Dynamics (CFD) to investigate the roughness effect on ship resistance (e.g. Demirel et al., 2014; Demirel et al., 2017b; Farkas et al., 2018; Song et al., 2019a) and propeller performance (Owen et al., 2018; Song et al., 2019b), as well as ship self-propulsion characteristics (Song et al., 2020). The merit of using CFD is that the distribution of the local friction velocity, $u_{\tau}$, can be dynamically computed for each discretised cell, and therefore the dynamically varying roughness Reynolds number, $\mathrm{k}^{+}$, and corresponding roughness function, $\Delta U^{+}$, can be considered in the computation. The three-dimensional (3D) effects can also be taken into account and the simulations are free from the scale effects if they are modelled in full-scale.

Great effort has been made to assess the roughness effect on skin friction, however, there is little research applied to a ship model experimentally. Kiosidou et al. (2017) performed tank testing of a flat plate and a model ship, both in smooth and rough conditions, where the rough surface was created by applying sandpapers. From the flat plate test, they obtained the roughness function of the sandpaper surfaces, and extrapolated the frictional resistance to a $180 \mathrm{~m}$ ship using Granville's similarity law scaling procedure. They scaled the rough ship results to the same $180 \mathrm{~m}$ ship using the resistance formula of Schlichting (2017). The results obtained by the above-mentioned two methods were compared against each other. The comparison suggested the two results do not agree with each other well. However, they did not directly compare the extrapolated result with the experimental results for the model-scale rough ship, and hence could not provide a good validation of Granville's similarity law analysis.

The literature suggests that Granville's scaling method is still the most widely used method to predict the roughness effect on ship resistance, owing to its merit that this method can predict the roughness effect on the frictional resistance for ships of arbitrary lengths and speeds. Also, the recent CFD studies show good agreement with the results obtained by Granville's extrapolation (Demirel et al., 2017b, Song et al., 2019a). Considering the computational cost for the CFD studies, as well as the fact that the simulations can only be conducted for one ship length at once, Granville's similarity law scaling is still an economical and robust method.

As mentioned earlier, however, this method can only predict the frictional resistance of a flat plate of the given length. Recent studies claim that the other resistance components for a ship-shape body, such as viscous pressure resistance and wave making resistance, are also affected by the roughness effect (Demirel et al., 2017b; Song et al., 2019a). Therefore, it is worthwhile to conduct an experiment using a ship model with a rough surface, and compare the results with those predicted using Granville's extrapolation to check the validity of this scaling method for predicting the roughness effect on ship resistance.

To the best of the authors' knowledge, there exists no specific study comparing the ship resistance predicted following Granville's scaling procedure with the resistance measured directly from a rough model ship tank test. Therefore, this study aims to fill this gap by conducting towing tests using a flat plate and a model ship, both in smooth and rough conditions.

In this study, towing tests involving a flat plate and model ship were performed in smooth and rough surface conditions. From the towed plate tests, the roughness function for the given surface roughness was determined and then used in order to scale the frictional resistance to the length of the ship model. Then the total resistance coefficients of the ship model were predicted and compared with the experimental results measured from the model ship towing test in the rough condition. 


\section{Methodology}

\subsection{Approach}

Figure 1 schematically illustrates the methodology used in this study. The first step of this study is conducting four different towing tests using a flat plate and a model ship, both in smooth and rough surface conditions. In order to roughen the surfaces, the same sand grit (aluminium oxide abrasive powder) was applied to the surfaces of the plate and the model ship. The second step is the determination of the roughness functions. The roughness functions for the given surface roughness were calculated using the indirect method for flat plates, presented by Granville (1987). The third step is extrapolating the rough frictional resistance $\left(C_{F, r}\right)$ from the plate length $(1.5 \mathrm{~m})$ to the model ship length $(3.0 \mathrm{~m})$, following the boundary layer similarity law scaling procedure, presented by Granville $(1958 ; 1978)$. The final step is predicting the total resistance of the rough model ship $\left(C_{T, r}\right)$ using the extrapolated flat plate frictional resistance and the smooth ship results. The predicated rough ship resistance is then compared with the measured rough ship resistance $\left(C_{T, r}\right)$. Both $2 D$ method and $3 D$ method are adopted in the prediction of the rough ship resistance, where the $2 D$ method only considers the roughness effect on the frictional resistance while the $3 D$ method considers the viscous pressure resistance as well.

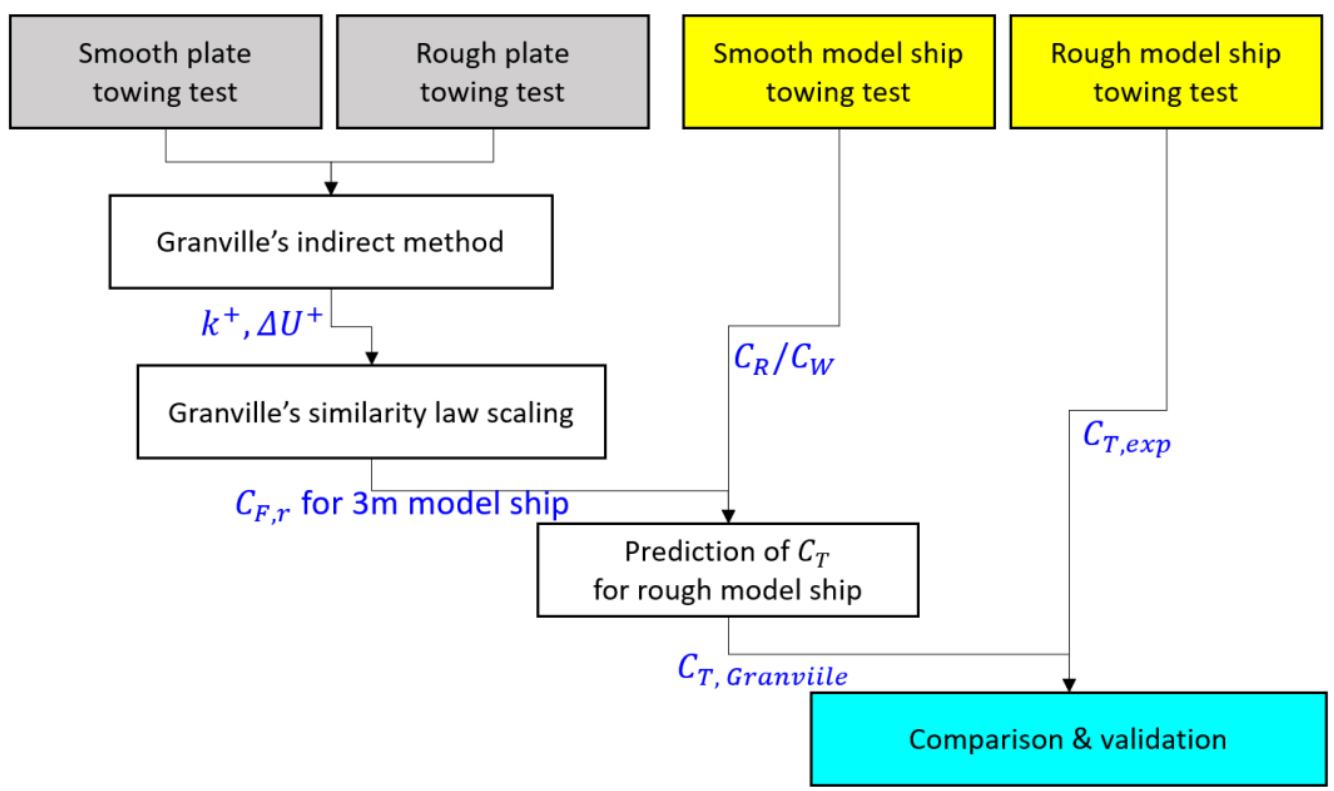

Figure 1 Schematic illustration of the current methodology

\subsection{Experimental setup}

\subsubsection{Towing tank}

The towing tests were conducted in the Kelvin Hydrodynamics Laboratory of the University of Strathclyde. The tank has a dimension of $76.0 \mathrm{~m}(\mathrm{~L}) \times 4.6 \mathrm{~m}(\mathrm{~W}) \times 2.5 \mathrm{~m}(\mathrm{D})$. The tank is equipped with a digitally controlled towing carriage, a state-of-the-art absorbing wave maker, and a highly effective sloping beach. The carriage has a velocity range of $0-5 \mathrm{~m} / \mathrm{s}$. Fresh water was used in the experiments, wherein the water temperature was monitored during the tests. Figure 2 shows the towing carriage in the KHL. 


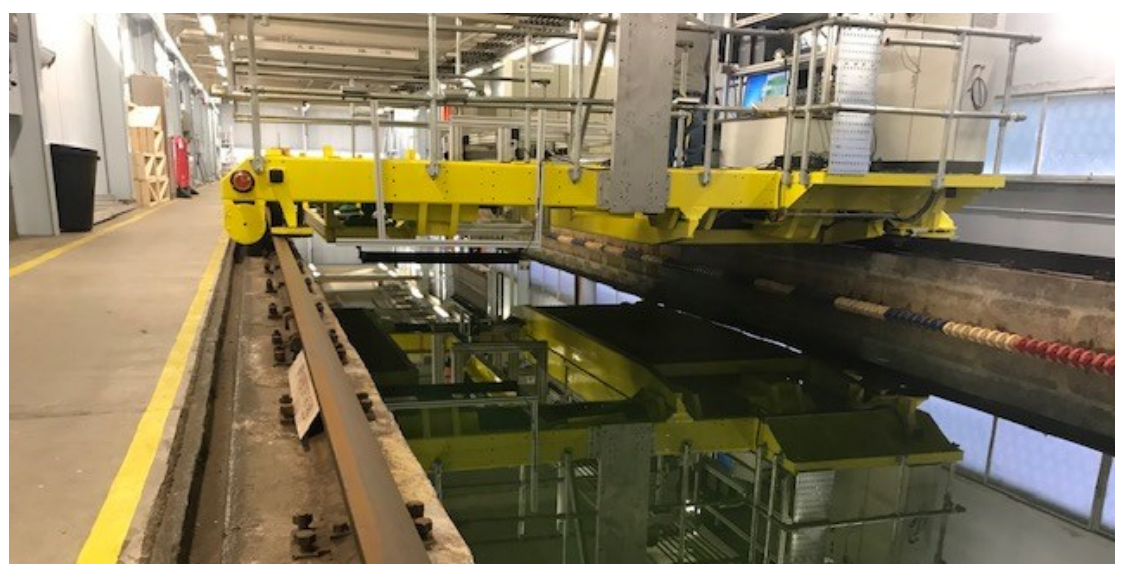

Figure 2 The towing carriage of the Kelvin Hydrodynamics Laboratory

\subsubsection{Flat plate towing test}

The flat plate used in this study was manufactured from 304 stainless steel grade sheet stock. Figure 3 illustrates the experimental setup used for the flat plate towing test. The plate has a thickness of $5 \mathrm{~mm}$, and the leading edge of the plate was shaped to a radius of $2.5 \mathrm{~mm}$ while the trailing edge was kept sharp. The flatness of the plates, as well as their dimensions were checked using a CNC (Computer Numerical Control) machine. After being smoothened and polished, the plate was installed on a custom-built test rig on the towing carriage, and it was carefully aligned with the centreline of the tank in order to minimise side forces.

The flat plate was towed in smooth condition first, at the speed range of $1.5-4.5 \mathrm{~m} / \mathrm{s}$. After finishing the smooth plate test, the same plate was coated with Clarke Aluminium Oxide Abrasive Powder, 60-80 grit, to create a rough surface. Then towing tests in the rough condition were carried out at the same speed range. Figure 4 shows the smooth flat plate and the same plate coated with the sand grit (aluminium oxide abrasive powder). The details of the measurement of the surface roughness and the choice of the representative roughness height, $k$, can be found in section 3.3.

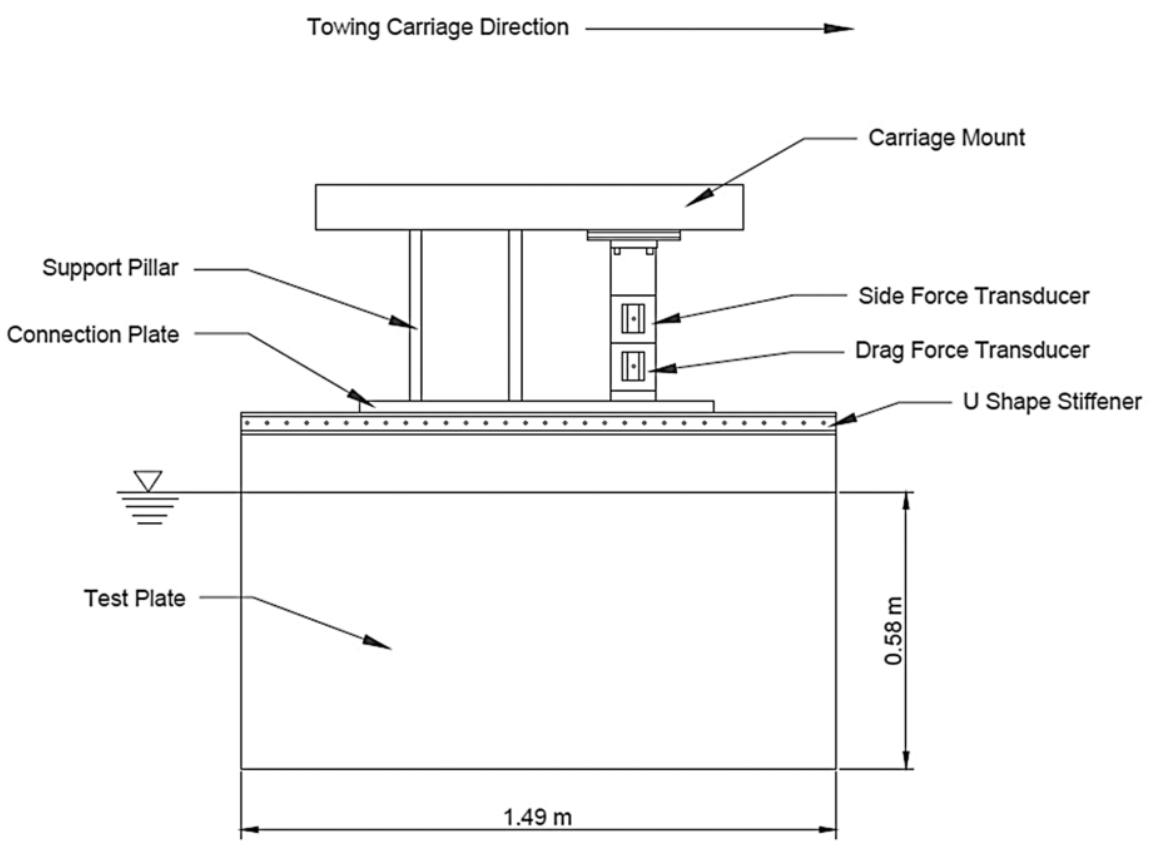




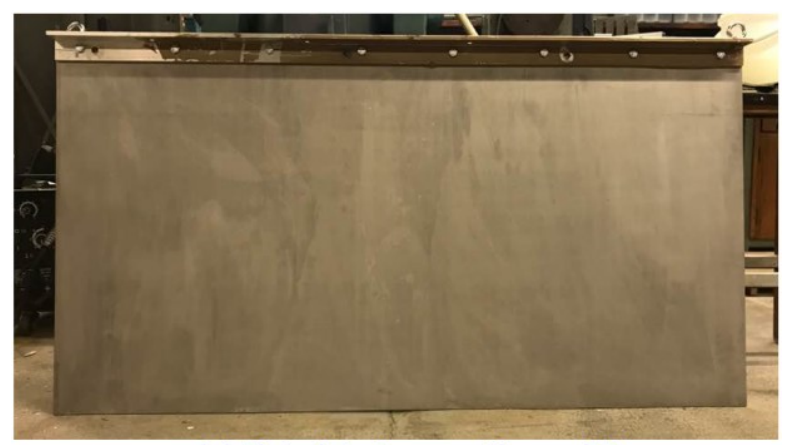

(a) Flat plate in smooth condition

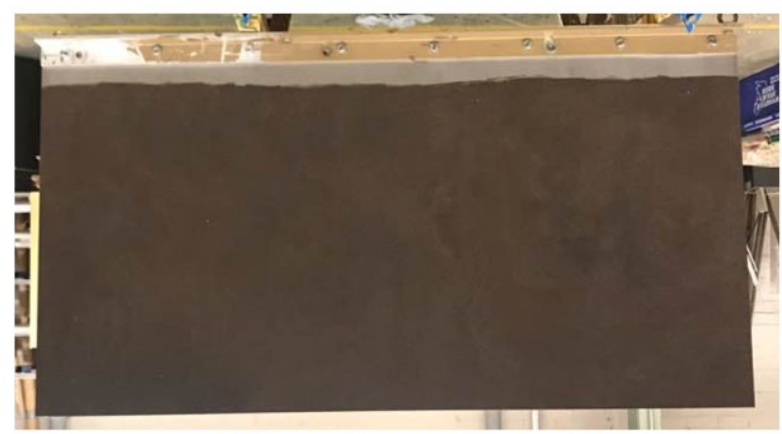

(b) Flat plate in rough condition

Figure 4 Flat plate used in this study, (a) smooth condition, (b) rough condition

\subsubsection{Model ship towing test}

In this study, a model of the KRISO Container Ship (KCS) was used for the model ship towing tests. The principal particulars of the KCS are given in Table 1. The model was built at a scale factor of 75 and towed without a rudder or appendages. Figure 5 illustrates the experimental setup used for the towing tests. During the test, the model was free to trim and sink. Two Linear Variable Differential Transducers (LVDT) were used to measure the sinkage at the midship point and the stern, then using the sinkage values at the two points, the trim angle was calculated using trigonometry. A load cell was attached at the tow point to measure the total resistance of the model ship.

As with the flat plate towing test, the model ship was first towed in smooth condition (at the speed range of 1.0$1.5 \mathrm{~m} / \mathrm{s}$ ). After the smooth towing test, the model ship was coated with the same sand grit (aluminium oxide abrasive powder) as applied to the flat plate. Then the rough model ship was towed at the same speed range. Figure 6 shows the smooth model ship and the same model ship in the rough condition.

Table 1 Principal particulars of the KCS in full-scale adapted from Kim et al. (2001) and Larsson et al. (2013).

\begin{tabular}{llrr}
\hline Parameters & & Full-scale & Model-scale \\
\hline Scale factor & $\lambda$ & 1 & 75 \\
Length between the perpendiculars & $L_{P P}(\mathrm{~m})$ & 230 & 3.0667 \\
Length of waterline & $L_{W L}(\mathrm{~m})$ & 232.5 & 3.1 \\
Beam at waterline & $B_{W L}(\mathrm{~m})$ & 32.2 & 0.4293 \\
Depth & $D(\mathrm{~m})$ & 19.0 & 0.2533 \\
Design draft & $T(\mathrm{~m})$ & 10.8 & 0.144 \\
Wetted surface area w/o rudder & $S\left(\mathrm{~m}^{2}\right)$ & 9424 & 1.6753 \\
Displacement & $\nabla\left(\mathrm{m}^{3}\right)$ & 52030 & 693.733 \\
Block coefficient & $C_{B}$ & 0.6505 & 0.6505 \\
Design speed & $V(\mathrm{knot}, \mathrm{m} / \mathrm{s})$ & 24 & 1.426 \\
Froude number & $F_{n}$ & 0.26 & 0.6505 \\
Centre of gravity & $K G(\mathrm{~m})$ & 7.28 & 0.0971 \\
Metacentric height & $G M(\mathrm{~m})$ & 0.6 & 0.008 \\
\hline
\end{tabular}




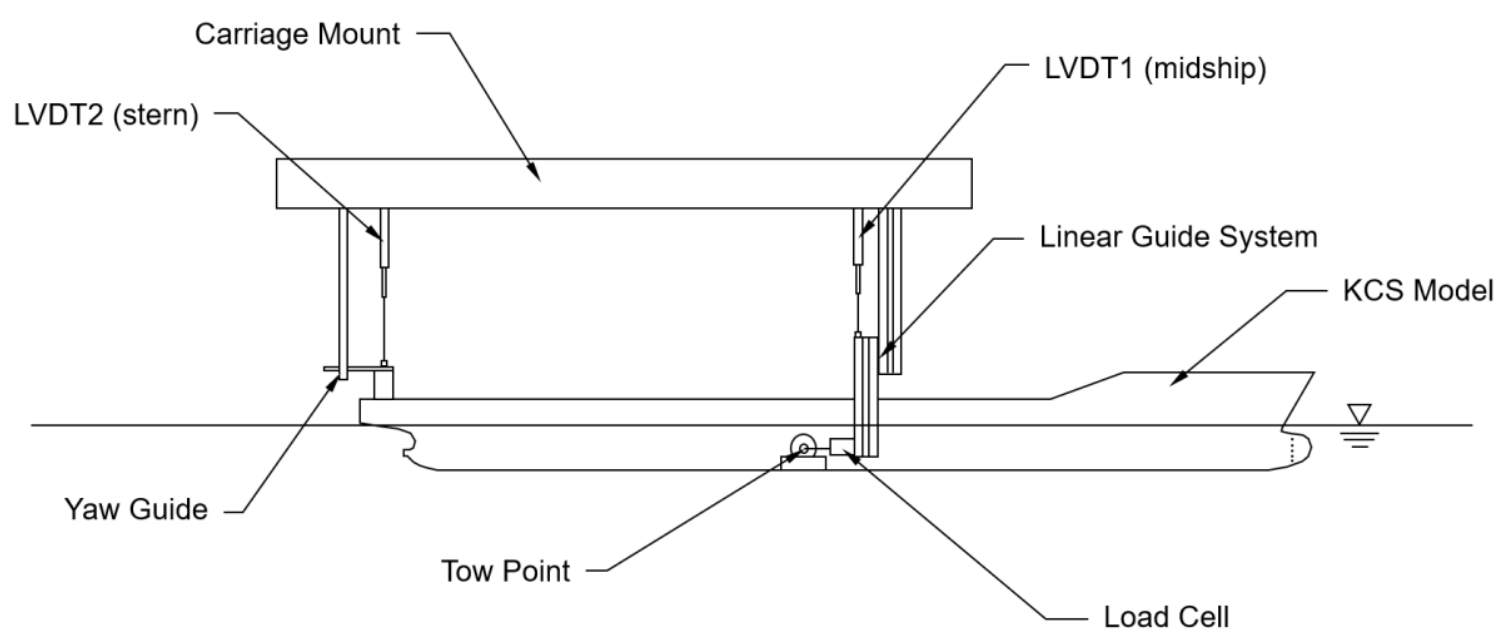

Figure 5 Experimental set up for model ship towing test

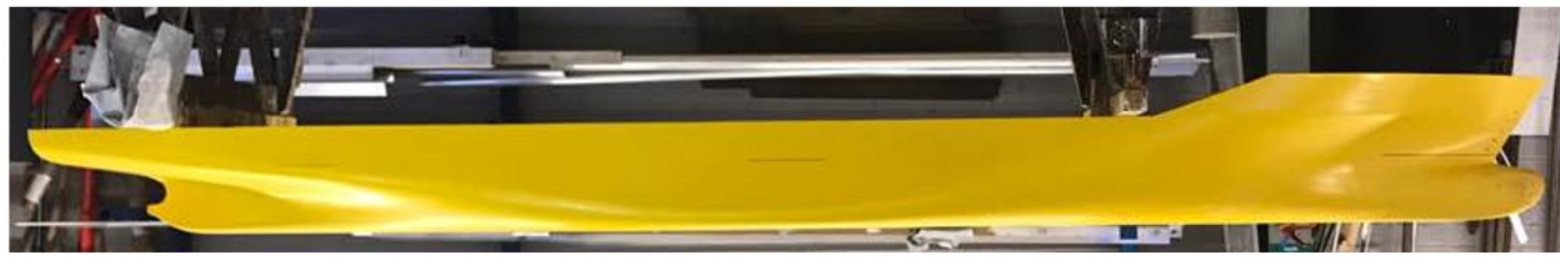

(a) KCS model in smooth condition

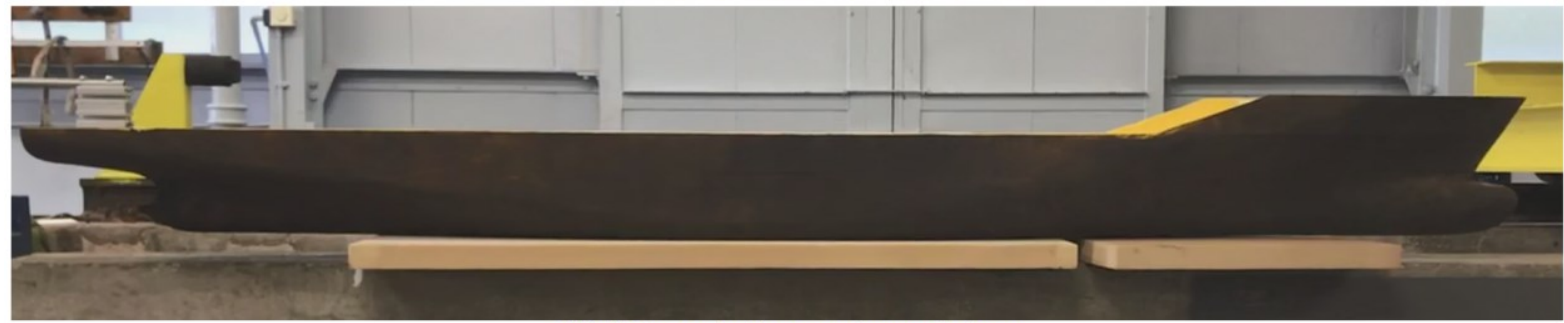

(b) KCS model in rough condition

Figure 6 KCS model used in this study (a) smooth condition, (b) rough condition

\subsection{Roughness function determination}

The roughness function for the given surface roughness was obtained using the results from the flat plate tests. To separate the frictional resistance coefficient, $C_{F}$, of the towed plates from the total resistance coefficient, $C_{T}$, the following assumptions were made: i) The total resistance values of the flat plates consist of the frictional resistance, $C_{F}$, and the residuary resistance coefficient, $C_{R}$; ii) the frictional resistance of the smooth plate, $C_{F}$, follows the Kàrmàn-Schoenherr friction line (Schoenherr, 1932), as

$$
\frac{0.242}{\sqrt{C_{F}}}=\log \left(R e_{L} C_{F}\right)
$$

where, $R e_{L}$ is the Reynolds number based on the length of the plate; iii) the residuary resistance values, $C_{R}$, are functions of the Froude number, $F_{n}$, and the roughness effect on $C_{R}$ is negligible.

Using the above assumptions, the frictional resistance for the rough flat plate can be determined as

$$
\begin{gathered}
C_{R, S}=C_{T, S}-C_{F, S} \\
C_{R, r}=C_{R, s}
\end{gathered}
$$




$$
C_{F, r}=C_{T, r}-C_{R, S}
$$

where, the second subscript ' $s$ ' and ' $r$ ' indicate the smooth and rough surface conditions, respectively. It is of note that this calculation is only valid for the $C_{F}$ values obtained at the same Froude number, $F_{n}$, and hence the same towing speed in this study.

Using the obtained frictional resistance values for the rough plate, $C_{F, r}$, the roughness functions, $\Delta U^{+}$, and the corresponding roughness Reynolds number, $k^{+}$, were calculated following the indirect roughness determination procedure for towed plates, also known as the overall method, which was proposed by Granville (1958; 1987). In this method, the $k^{+}$and $\Delta U^{+}$values can be determined as follows.

$$
\begin{gathered}
\Delta U^{+}=\sqrt{\frac{2}{C_{F, S}}}-\sqrt{\frac{2}{C_{F, r}}}-19.7\left(\sqrt{\frac{C_{F, S}}{2}}-\sqrt{\frac{C_{F, r}}{2}}\right)-\frac{1}{\kappa} \Delta U^{+^{\prime}} \sqrt{\frac{C_{F, r}}{2}} \\
k^{+}=\left(\frac{k}{L}\right)\left(\frac{R e_{L} C_{F}}{2}\right) \sqrt{\frac{2}{C_{F, r}}}\left[1-\frac{1}{\kappa} \sqrt{\frac{2}{C_{F, r}}}+\frac{1}{\kappa}\left(\frac{3}{2 \kappa}-\Delta U^{+^{\prime}}\right) \frac{C_{F, r}}{2}\right]
\end{gathered}
$$

where, $\kappa$ is the von Kàrmàn constant and $\Delta{U^{+}}^{\prime}$ is the slope of the roughness function as a function of $\ln k^{+}$, and $k$ is the representative roughness height.

\subsection{Granville's boundary layer similarity law scaling}

In order to scale the frictional resistance coefficient of the $1.5 \mathrm{~m}$ rough plate to the $3 \mathrm{~m}$ model ship, the similarity law scaling procedure of Granville $(1958 ; 1978)$ was used with the $C_{F, r}, \Delta U^{+}$, and $k^{+}$values obtained from the flat plate towing tests.

Figure 7 schematically illustrates the scaling procedure used in this study following Granville's similarity law analysis. The first step is drawing a smooth friction coefficient line, $C_{F, S}$, against $\log R e_{L}$. In this study, the Kàrmàn-Schoenherr friction line was used (Equation 1). The second step is shifting the smooth friction line by $\Delta U^{+} \kappa / \ln (10)$ in the $\log R e_{L}$ direction, in order to represent the rough friction coefficient, $C_{F, r}$. The third step is plotting the line of the constant $L_{\text {plate }}^{+}$value satisfying the following equation.

$$
R e_{L}=\frac{L_{\text {plate }}^{+}}{\sqrt{\frac{C_{F}}{2}}\left(1-\frac{1}{\kappa} \sqrt{\frac{C_{F}}{2}}\right)}
$$

where $L_{\text {plate }}^{+}$is a non-dimensional length of the plate defined by

$$
L_{\text {plate }}^{+}=\frac{L_{\text {plate }} U_{\tau}}{v}
$$

The fourth step is shifting the line of constant $L_{\text {plate }}^{+}$by $\log \left(L_{\text {model ship }} / L_{\text {plate }}\right)$ in the $\log R e_{L} \operatorname{direction}$. This line

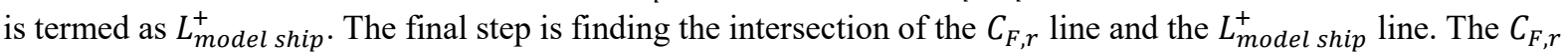
and $R e_{L}$ values at the intersection represent the frictional resistance of the KCS model, and the corresponding Reynolds number, respectively. 


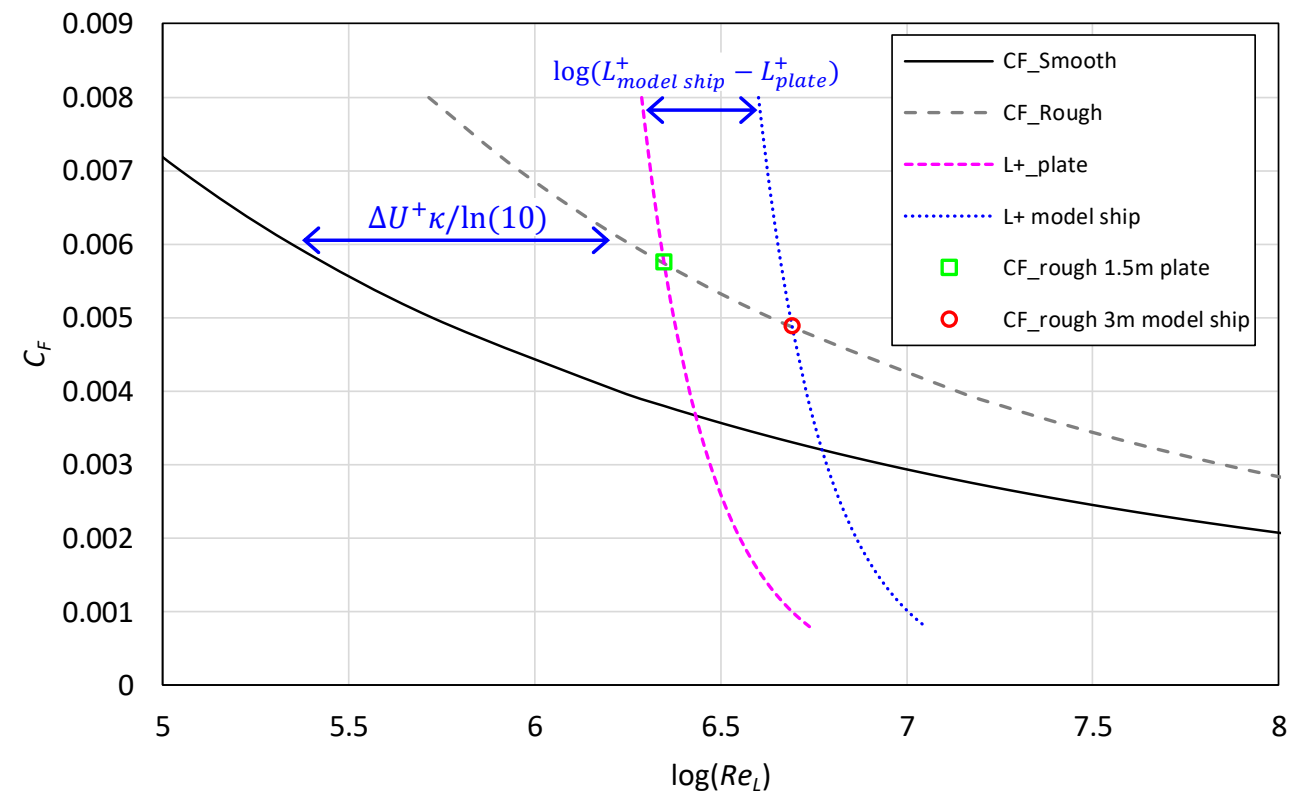

Figure 7 Schematic of Granville's similarity law scaling procedure

\subsection{Uncertainty analysis}

Uncertainty analysis was conducted to estimate the uncertainties of the measurements in the tests, following the ITTC recommended procedures (ITTC, 2014). The precision limits were determined through repeatability test at the lowest and highest towing speeds, while the bias limits were calculated considering the uncertainties associated with calibration, data acquisition, data reduction and conceptual bias.

Table 2 shows the absolute and relative overall uncertainties of the measurements at the lowest speed and the highest speed. As shown in the table, the overall $95 \%$ confidence limits for the frictional resistance for the rough plate, $C_{F, r}$, were $\pm 2.2 \%$ and $\pm 0.9 \%$ at the lowest and highest speeds, respectively. And the overall uncertainties for the roughness functions, $\Delta U^{+}$, were $\pm 5.5 \%$ and $\pm 0.5 \%$, at the lowest and highest speeds, respectively, while the uncertainties for the total resistance of the rough model ship, $C_{T, r}$, were $\pm 2.1 \%$ and $\pm 1.7 \%$, respectively.

Table 2 Overall uncertainties of the measurements with 95\% confidence level, where $\tau$ and $\sigma$ are trim and sinkage, respectively

\begin{tabular}{|c|c|c|c|c|c|}
\hline & \multirow[b]{2}{*}{ Parameter } & \multicolumn{2}{|l|}{ Lowest speed } & \multicolumn{2}{|l|}{ Highest speed } \\
\hline & & Overall Uncertainty & $\%$ & Overall Uncertainty & $\%$ \\
\hline \multirow[t]{5}{*}{ Flat plate } & $C_{T, S}$ & $\pm 9.07 \mathrm{E}-05$ & $\pm 2.1 \%$ & $\pm 3.21 \mathrm{E}-05$ & $\pm 0.9 \%$ \\
\hline & $C_{F, S}$ & $\pm 6.92 \mathrm{E}-06$ & $\pm 0.2 \%$ & $\pm 6.24 \mathrm{E}-07$ & $\pm 0.02 \%$ \\
\hline & $C_{T, r}$ & $\pm 9.10 \mathrm{E}-05$ & $\pm 1.4 \%$ & $\pm 4.36 \mathrm{E}-05$ & $\pm 0.7 \%$ \\
\hline & $C_{F, r}$ & $\pm 1.29 \mathrm{E}-04$ & $\pm 2.2 \%$ & $\pm 5.41 \mathrm{E}-05$ & $\pm 0.9 \%$ \\
\hline & $\Delta U^{+}$ & $\pm 2.76 \mathrm{E}-01$ & $\pm 5.5 \%$ & $\pm 3.72 \mathrm{E}-02$ & $\pm 0.5 \%$ \\
\hline \multirow[t]{6}{*}{ Model ship } & $C_{T, S}$ & $\pm 6.09 \mathrm{E}-05$ & $\pm 1.4 \%$ & $\pm 4.95 \mathrm{E}-05$ & $\pm 1.0 \%$ \\
\hline & $\tau_{s}\left({ }^{o}\right)$ & $\pm 1.09 \mathrm{E}-01$ & $\pm 10.8 \%$ & $\pm 2.00 \mathrm{E}-01$ & $\pm 8.9 \%$ \\
\hline & $\sigma_{s}(\mathrm{~mm})$ & $\pm 2.65 \mathrm{E}-01$ & $\pm 8.0 \%$ & $\pm 4.25 \mathrm{E}-01$ & $\pm 4.4 \%$ \\
\hline & $C_{T, r}$ & $\pm 1.20 \mathrm{E}-04$ & $\pm 2.1 \%$ & $\pm 1.16 \mathrm{E}-04$ & $\pm 1.7 \%$ \\
\hline & $\tau_{r}\left(^{\mathrm{o}}\right)$ & $\pm 1.02 \mathrm{E}-01$ & $\pm 11.3 \%$ & $\pm 1.84 \mathrm{E}-01$ & $\pm 10.5 \%$ \\
\hline & $\sigma_{r}(\mathrm{~mm})$ & $\pm 2.39 \mathrm{E}-01$ & $\pm 7.8 \%$ & $\pm 4.28 \mathrm{E}-01$ & $\pm 5.3 \%$ \\
\hline
\end{tabular}




\section{Results}

\subsection{Flat plate towing test}

Figure 8 compares the total resistance coefficients and the frictional resistance coefficients for the smooth and rough plates obtained from the towing tests. As mentioned earlier (Equation 1-4), the difference between the smooth $C_{T}$ obtained from the towing test and the theoretical $C_{F}$ was defined as the residuary resistance, $C_{R}$. Then the frictional resistance for the rough plate was determined as the difference between the total resistance and the residuary resistance at the same speed $\left(C_{F, r}=C_{T, r}-C_{R}\right)$.

As shown in Figure 8, the frictional resistance of the rough plate first increases with increasing Reynolds number and tends to converge around $R e_{L}=3.5 \times 10^{6}$ (i.e. $C_{F, r}$ is independent of $R e_{L}$ ), suggesting the fully rough regime is reached beyond this point, whereas the values below remain in the transitionally rough regime (Flack and Schultz, 2014).

The increases in $C_{F}$ of the flat plates due to the roughness effect were observed to be $50 \%$ and $94 \%$ at the lowest and the highest speeds, respectively.

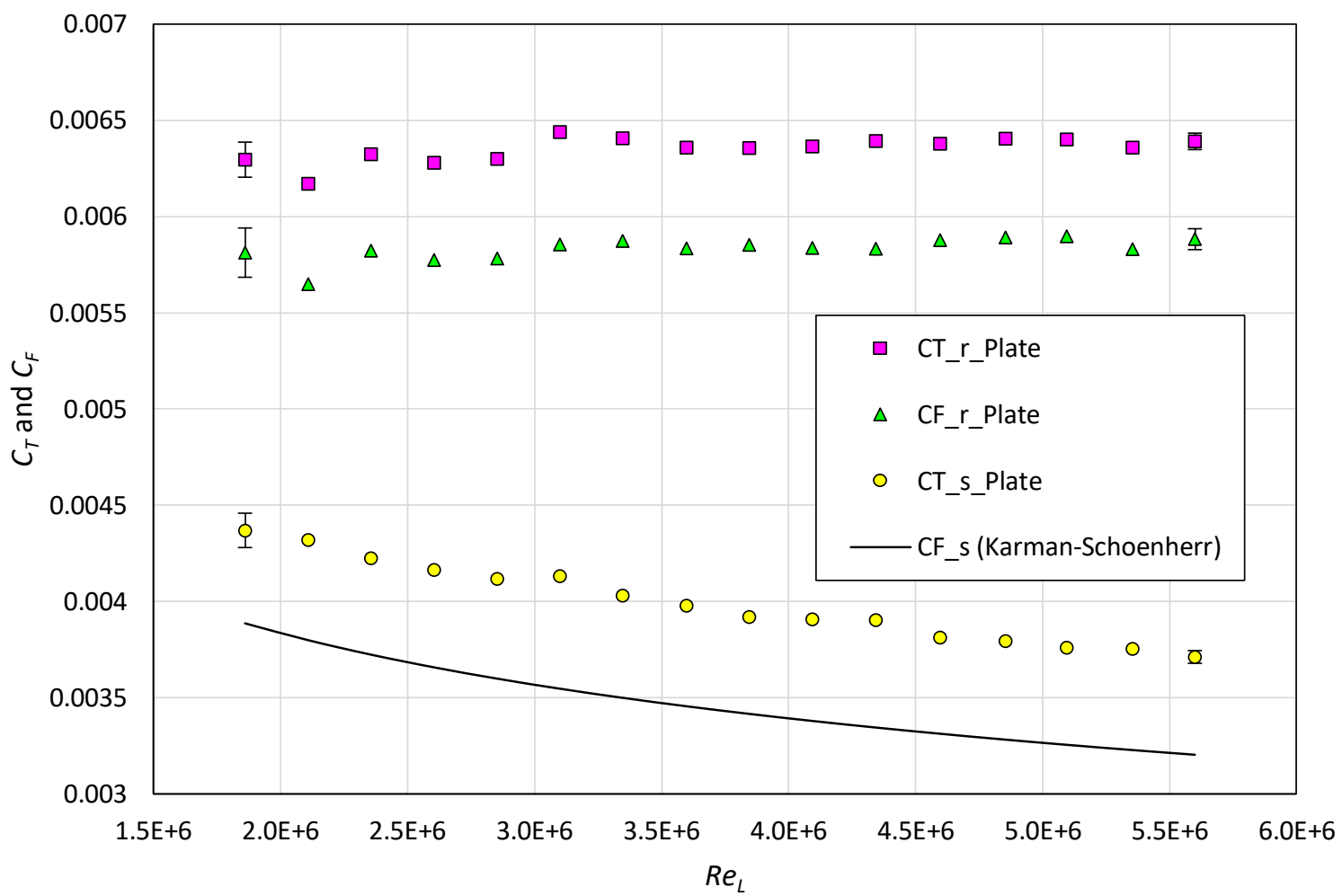

Figure $8 C_{T}$ and $C_{F}$ values of the flat plate in smooth and rough conditions

\subsection{Model ship towing test}

Figure 9 shows the total resistance coefficient values, $C_{T}$, obtained from the towed model ship in the smooth and rough conditions. As can be seen, both the smooth and rough $C_{T}$ show similar overall trends, while the magnitude of the rough $C_{T}$ is significantly higher than that of the smooth $C_{T}$. The increases in $C_{T}$ values due to the roughness effect were observed to be $30 \%$ and $32 \%$ at the lowest and highest speeds, respectively.

Figure 10 compares the trim, $\tau$, of the smooth and rough model ships, as well as the sinkage, $\sigma$, measured at the midship point $\left(\sigma_{\text {midship }}\right)$ and the stern of the model ship $\left(\sigma_{\text {stern }}\right)$. As observed in this figure, the roughness effect on the $\tau$ and $\sigma$ values are minor, but the effects increase with increasing speeds. The midship sinkage values, $\sigma$, 
for the rough hull were observed to be smaller than those of smooth hull, while the roughness effect on the stern sinkage was negligible. As a result, the trim angles, $\tau$, show decreases due to the roughness effect.

This effect of the surface roughness on the trim and sinkage is thought to be related to the pressure distribution, that is, the surface roughness altered the pressure distribution along the hull compared with the smooth case. This can be further investigated in detail using CFD simulations.

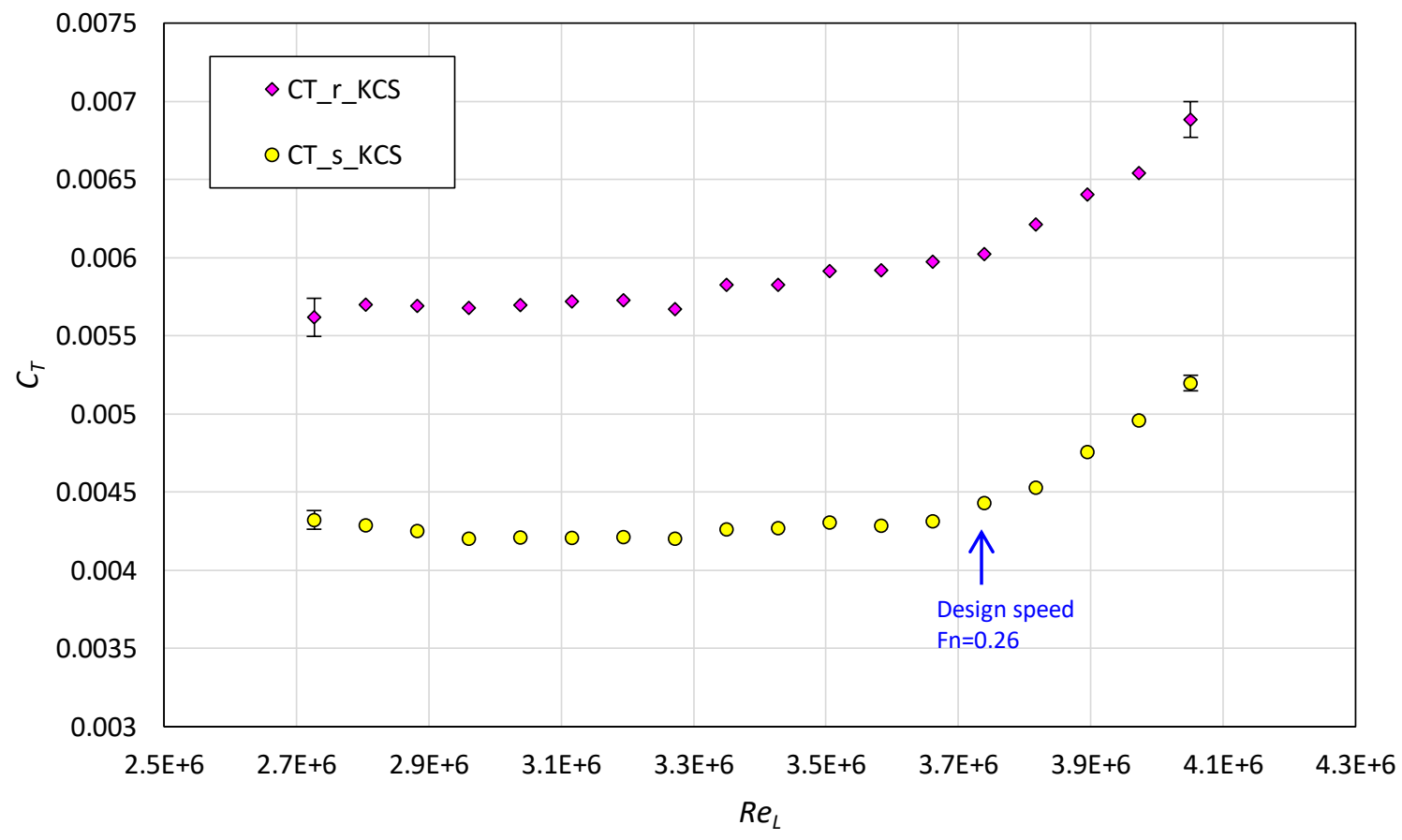

Figure $9 C_{T}$ values of the model ship in smooth and rough conditions 


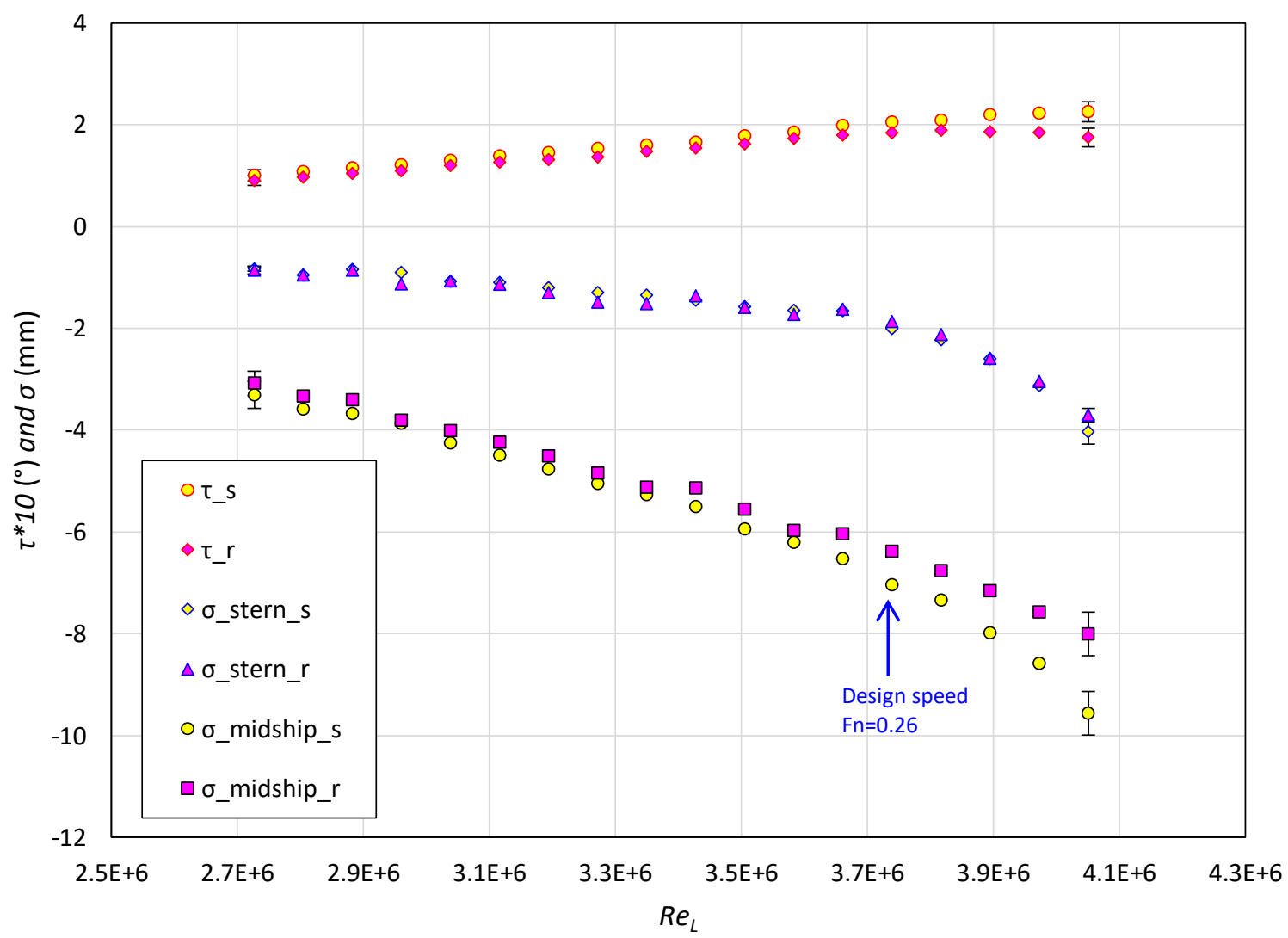

Figure $10 \tau$ and $\sigma$ values for the model ship in smooth and rough conditions

\subsection{Roughness function determination}

As explained in section 2.3, the results obtained from the flat plate towing tests were used to calculate the roughness function following the indirect method for towed plates (overall method), presented by Granville (1987). The surface roughness of the flat plate was measured using a TQC Sheen B.V. (C) Hull Roughness Gauge, which measures the maximum peak to trough roughness height over a $50 \mathrm{~mm}$ interval, $R t_{50}$, (TQC, 2019). The average $R t_{50}$ value of the plate was measured to be $353 \mu \mathrm{m}$.

Figure 11 compares the Colebrook type roughness function of Grigson (1992), the analytical fit of Cebeci and Bradshaw (1977) based on the sand grain roughness functions of Nikuradse (1933), and the roughness functions from the current study, based on the different choices of the representative roughness heights, $k$.

As shown in the figure, when the representative roughness height is chosen as $k=R t_{50}$, the roughness functions lie between Colebrook-type and Nikuradse-type roughness functions. When $k$ is set to $1.8 R t_{50}$, the roughness function shows excellent agreement with the Nikuradse roughness function. One the other hand, when $k=$ $0.4 R t_{50}$ is used, the roughness function showed deviations with the Colebrook-type roughness function at low $k^{+}$ regions. This can be mostly attributed to the fact that the current rough surfaces showed behaviours of the transitionally rough regime (Figure 8), resulting in inflectional behaviour in the roughness function. Therefore, a better agreement was achieved with the inflectional Nikuradse-type roughness function than the monotonic Colebrook type roughness function. For comparison, the results were also plotted using $k=0.75 R t_{50}$, which was suggested by Schultz and Flack (2003), for sandpaper roughness.

It is worthwhile to mention that in the current study the choice of the representative roughness height, $k$, does not affect the roughness function values, $\Delta U^{+}$, but only changes the roughness Reynolds number, $k^{+}$. Therefore, the choice of the representative roughness height does not affect any results of this study. 


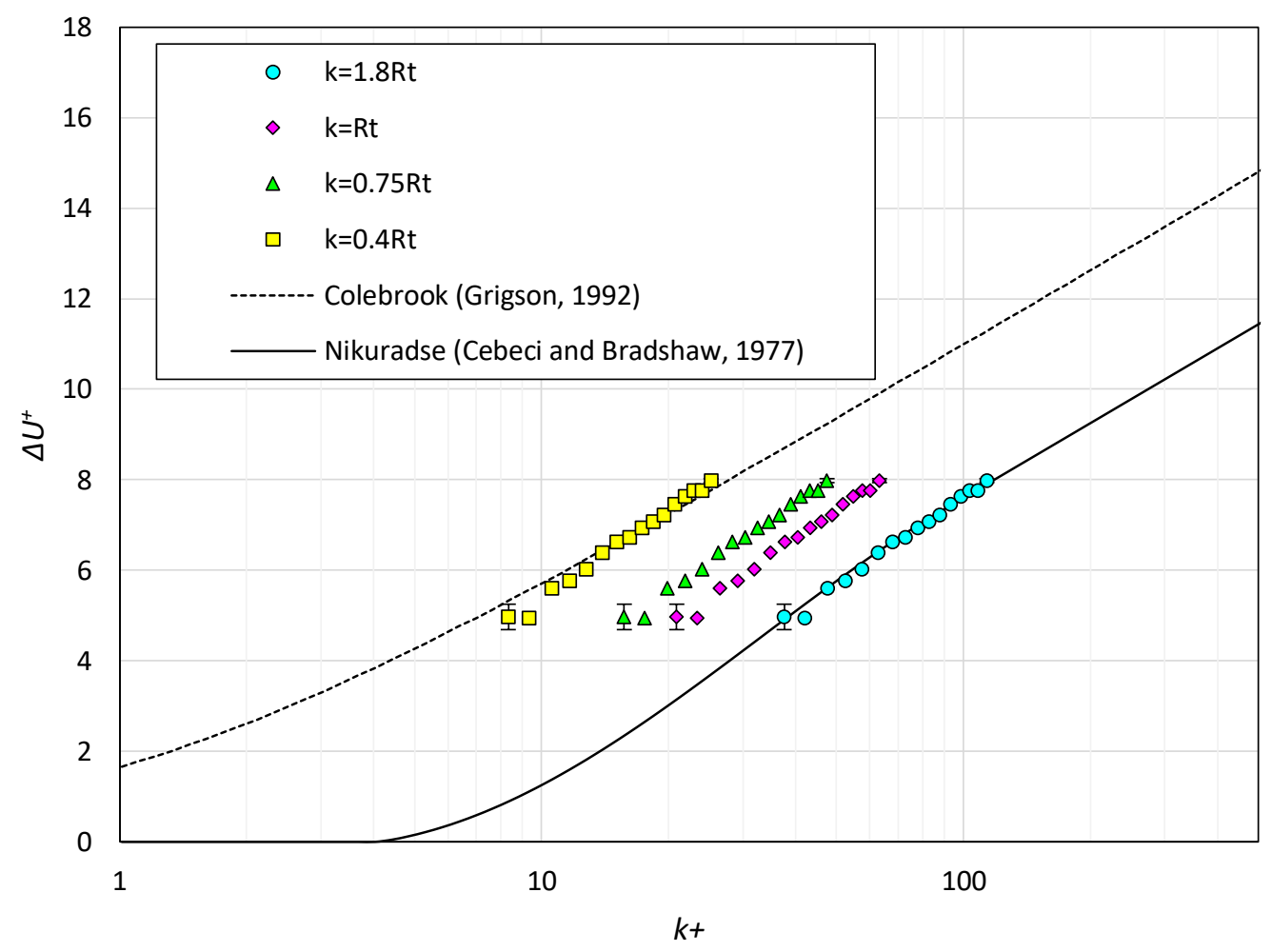

Figure 11 Roughness functions, based on the different choices of the representative roughness height

\subsection{Extrapolation of the frictional resistance}

As explained in section 2.4, the frictional resistance of the $1.5 \mathrm{~m}$ rough plate, $C_{F, r}$, was extrapolated to the length of the model ship $(3.0 \mathrm{~m})$ using the boundary layer similarity law analysis, proposed by Granville $(1958 ; 1978)$. The extrapolated $C_{F, r}$ values for the $3.0 \mathrm{~m}$ flat plate was assumed to be equal to that of the model ship in the rough condition. In the extrapolation procedure the Nikuradse type roughness function model of Cebeci and Bradshaw (1977) was used (with the use of $k=1.8 R t_{50}$ ), rather than using the discrete $\Delta U^{+}$values, to ensure that the extrapolated speed range covers the towing speeds of the model ship. Figure 12 compares the frictional resistance for the rough flat plate obtained from the towing test and the extrapolated $C_{F, r}$ values for the model ship.

Shown for comparison in Figure 13 is the extrapolated frictional resistance, $C_{F, r \text {, Granville }}$ for the model ship, smooth frictional resistance, $C_{F, S}$, obtained from the Kàrmàn-Schoenherr friction line, and the total resistance coefficients, $C_{T, S}$ and $C_{T, r}$ measured from the towing tests. It is of note that the increases in the frictional resistance for the model ship were $33 \%$ and $46 \%$ at the lowest and highest towing speeds of the model ship, respectively. 


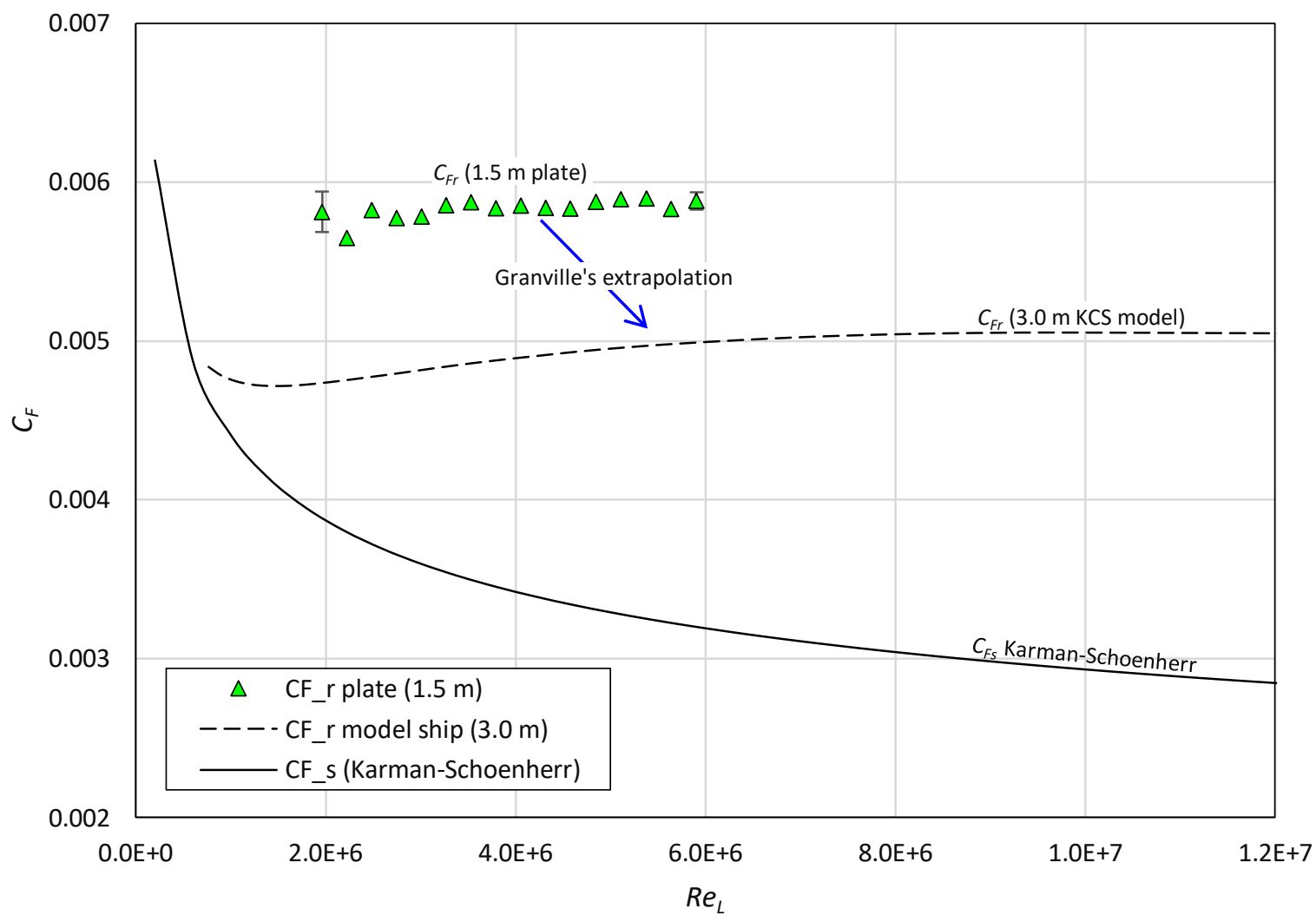

Figure $12 C_{F, r}$ values for the rough plate and the extrapolated $C_{F, r}$ for the rough $\mathrm{KCS}$ model using Granville's similarity law scaling 


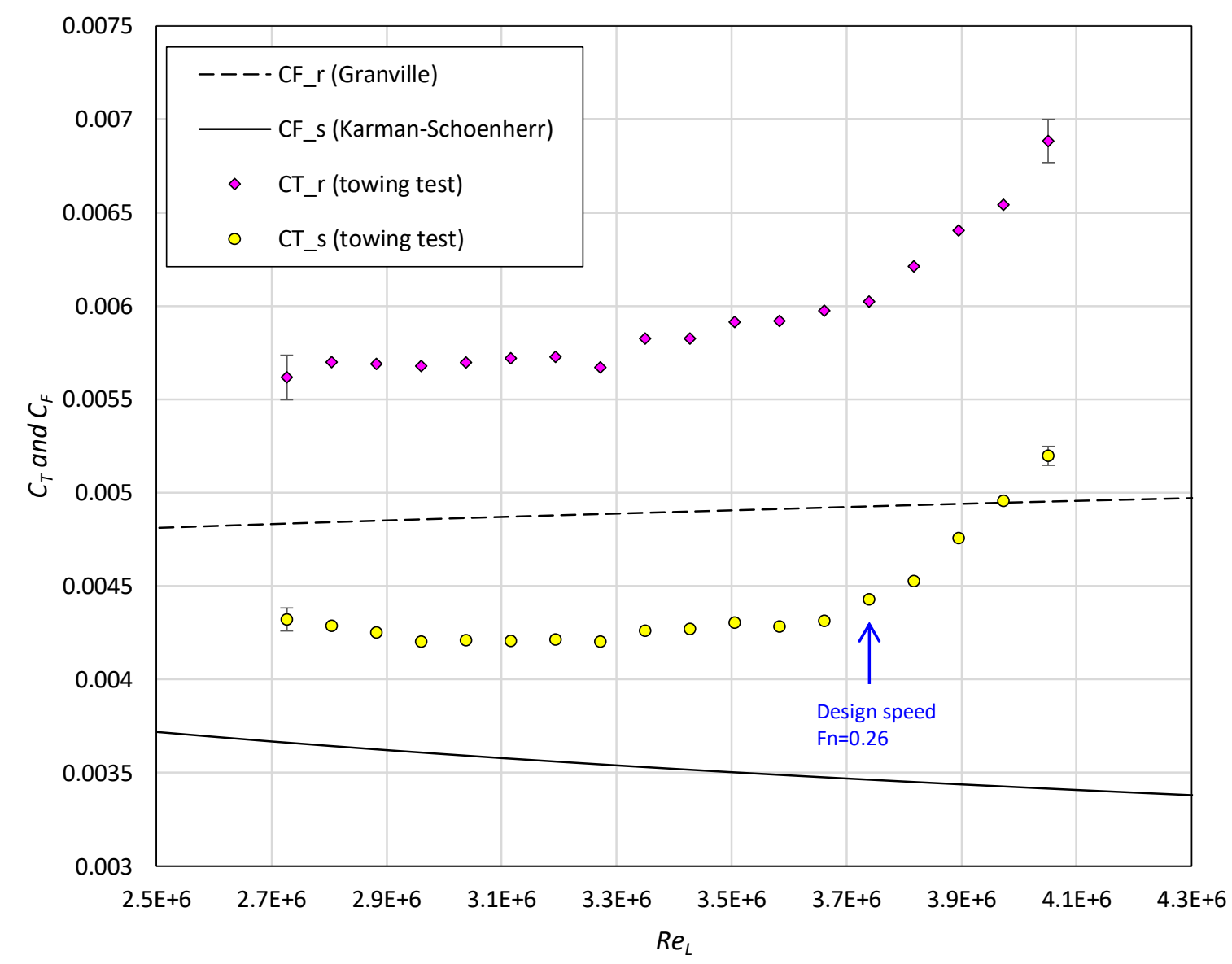

Figure $13 C_{T}$ and $C_{F}$ values for the model ship in smooth and rough conditions

\subsection{Prediction for the total resistance and comparison with the experiment}

Using the extrapolated frictional resistance values for the rough model ship $\left(C_{F, r, \text { Granville }}\right)$, the total resistance coefficient in the rough condition, $C_{T, r}$, was predicted and compared with the experimental results obtained from the model ship towing test in the rough condition. Two different methods were used for the prediction, namely the $2 D$ method and the $3 D$ method.

In the $2 D$ method, which considers the roughness effect on the frictional resistance only, the ship total resistance was considered to consist of the sum of the frictional resistance and the residuary resistance $\left(C_{T}=C_{F}+C_{R}\right)$. The residuary resistance is assumed to be independent of the surface roughness. Then the total resistance for the rough model ship, $C_{T, r, 2 D}$, is determined by

$$
\begin{gathered}
C_{R, S}=C_{T, S}-C_{F, S} \\
C_{R, r}=C_{R, S} \\
C_{T, r, 2 D}=C_{F, r, \text { Granville }}+C_{R, r}
\end{gathered}
$$

Equation 9 can be written alternatively as

$$
C_{T, r, 2 D}=C_{T, s}+\Delta C_{F}
$$

where, $\Delta C_{F}$ is the added resistance due to the surface roughness $\left(\Delta C_{F}=C_{F, r, \text { Granville }}-C_{F, S}\right)$. 
In the $3 D$ method, which considers the roughness effect on the frictional resistance and the viscous pressure resistance, the ship total resistance was considered to consist of the frictional resistance, the viscous pressure resistance and the wave making resistance $\left(C_{T}=C_{F}+C_{V P}+C_{W}\right.$, or $\left.C_{T}=(1+k) C_{F}+C_{W}\right)$, where $1+k$ is the form factor. The wave making resistance and the form factor were assumed to be independent of the surface roughness. Then the total resistance for the rough model ship, $C_{T, r, 3 D}$, is determined by

$$
\begin{gathered}
C_{W, S}=C_{T, S}-(1+k) C_{F, S} \\
C_{W, r}=C_{W, s} \\
C_{T, r, 3 D}=(1+k) C_{F, r, \text { Granville }}+C_{W, r}
\end{gathered}
$$

Equation 13 can be written alternatively as

$$
C_{T, r, 3 D}=C_{T, S}+(1+k) \Delta C_{F}
$$

For the calculation, the experimental form factor value of KCS, $1+k=1.2$, was used (Van et al., 2011).

Figure 14 compares the total resistance coefficients for the rough model ship, predicted from $2 D$ method and $3 D$ method, and the experimental $C_{T, r}$ values measured from the towing test. As shown in the figure, a good agreement was achieved between the experimental $C_{T, r}$ values and the predicted $C_{T, r}$ values. This suggests that the use of Granville's similarity law scaling method is valid for the prediction of the roughness effect on ship resistance.

It can be seen from the figure that, the results predicted using $3 D$ method show better agreement with the experimental data compared to those of $2 D$ method. Therefore, it can be deduced that the surface roughness not only increases the frictional resistance but also increases the viscous pressure resistance. This effect on the viscous pressure resistance has been also observed from the CFD simulations of Demirel et al. (2017b) and Song et al. (2019a) but has not been proven experimentally.

Another notable point is that the results from $3 D$ method, $C_{T, r, 3 D}$, are slightly overpredicted compared to the experimental results. This might be explained by the roughness effect on the form factor values, $1+k$. Song et al. (2019a) observed decreases in the $1+k$ values due to the roughness effect from the double body simulations. This implies that if the roughness effect on the form factor is considered together, the predicted $C_{T, r, 3 D}$ values can be more precise.

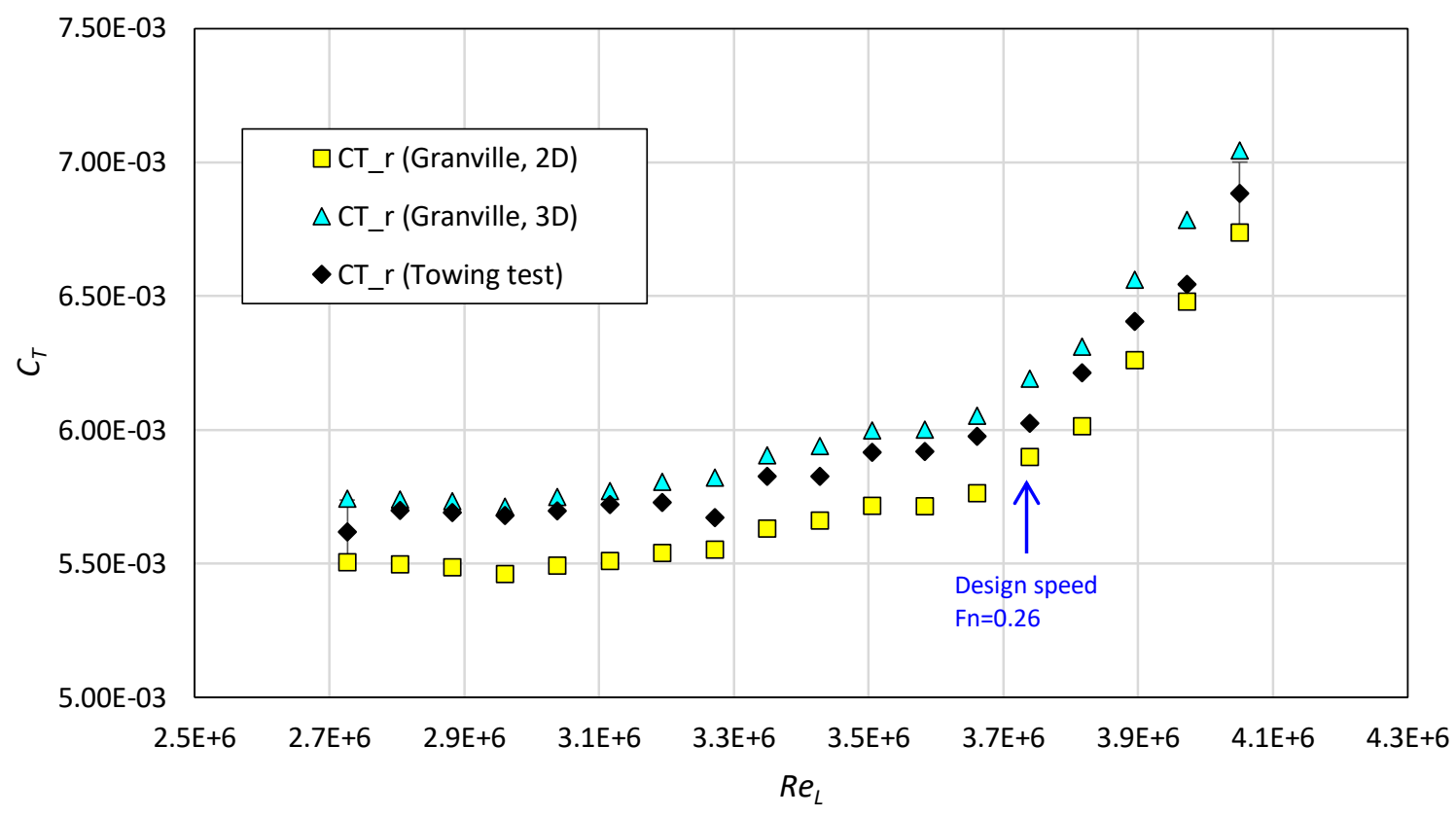




\section{Concluding remarks}

Towing tests involving a flat plate and a model ship were conducted in smooth and rough conditions for the investigation of the effect of roughness on ship resistance, as well as to validate the use of Granville's similarity law scaling. In order to roughen the surfaces of the plate and model ship, sand grit (aluminium oxide abrasive powder) was applied.

The plate and the model ship were towed in smooth and rough conditions at a range of speeds. Significant increases in the frictional resistance of the towed plate (up to 94\%) and the total resistance of the model ship (up to $32 \%$ ), were observed due to the rough surfaces, while changes in the trim and sinkage of the model ship were also identified.

The results of the towing tests were used to calculate the roughness function for the rough surface. Using the flat plate towing test results as well as the roughness function, the frictional resistance for the rough plate was extrapolated to the length of the model ship using Granville's similarity law scaling method.

Utilising the extrapolated result, the total resistance of the model ship in the rough condition was predicted. For the prediction, two different methods were used ( $2 D$ method and $3 D$ method). The predicted total resistance coefficients from both the methods showed good agreement with the results of the towing tests, suggesting that the use of Granville's similarity law scaling is valid for the prediction of roughness effect on ship resistance. The results also imply that the roughness effect on the viscous pressure resistance should be also considered for better prediction.

This study not only presents the investigations of the roughness effect on ship resistance, but also provides the first experimental validation of the use of Granville's similarity law scaling procedure for ship-shape bodies. Apart from Granville's similarity law scaling, there is increasing interest in the use of CFD simulations to predict the roughness effect on ship resistance. Therefore, future work may include a validation study for the CFD approach to the roughness effect, utilising the experimental data obtained in this study. 


\section{References}

Andrewartha, J., Perkins, K., Sargison, J., Osborn, J., Walker, G., Henderson, A., \& Hallegraeff, G. (2010). Drag force and surface roughness measurements on freshwater biofouled surfaces. Biofouling, 26, 487496.

Atlar, M., Yeginbayeva, I. A., Turkmen, S., Demirel, Y. K., Carchen, A., Marino, A., \& Williams, D. (2018). A Rational Approach to Predicting the Effect of Fouling Control Systems on "In-Service" Ship Performance. GMO SHIPMAR, 24(213), 5-36.

Benson, J., Ebert, J., \& Beery, T. (1938). Investigation in the NACA tank fo the effect of immersion in salt water on the resistance of plates coated with different shipbottom paints. NACA Memorandum Report $C \& R C-S 19-1$ (3).

Cebeci, T., \& Bradshaw, P. (1977). Momentum Transfer in Boundary Layer (Vol. -1).

Demirel, Y. K. (2015). Modelling the Roughness Effects of Marine Coatings and Biofouling on Ship Frictional Resistance. (PhD), University of Strathclyde, Glasgow.

Demirel, Y. K., Khorasanchi, M., Turan, O., Incecik, A., \& Schultz, M. P. (2014). A CFD model for the frictional resistance prediction of antifouling coatings. Ocean Engineering, 89, 21-31. doi: https://doi.org/10.1016/j.oceaneng.2014.07.017

Demirel, Y. K., Turan, O., \& Incecik, A. (2017b). Predicting the effect of biofouling on ship resistance using CFD. Applied Ocean Research, 62, 100-118. doi: https://doi.org/10.1016/j.apor.2016.12.003

Demirel, Y. K., Uzun, D., Zhang, Y., Fang, H.-C., Day, A. H., \& Turan, O. (2017a). Effect of barnacle fouling on ship resistance and powering. Biofouling, 33(10), 819-834. doi: 10.1080/08927014.2017.1373279

Demirel, Y. K., Song, S., Turan, O., \& Incecik, A. (2019). Practical added resistance diagrams to predict fouling impact on ship performance. Ocean Engineering, 106112. doi:https://doi.org/10.1016/j.oceaneng.2019.106112

Farkas, A., Degiuli, N., \& Martić, I. (2018). Towards the prediction of the effect of biofilm on the ship resistance using CFD. Ocean Engineering, 167, 169-186. doi: https://doi.org/10.1016/j.oceaneng.2018.08.055

Flack, K. A., Schultz, M. P., \& Shapiro, T. A. (2005). Experimental support for Townsend's Reynolds number similarity hypothesis on rough walls. Physics of Fluids, 17(3), 035102. doi: 10.1063/1.1843135

Flack, K. A., \& Schultz, M. P. (2014). Roughness effects on wall-bounded turbulent flows. Physics of Fluids, 26(10), 101305. doi:10.1063/1.4896280

Franzini, J. (1997). Fluid Mechanics with Engineering Aplications: 9th edition (9 ed.). New York: McGraw-Hill.

Granville, P. S. (1958). The frictional resistance and turbulent boundary layer of rough surfaces. J. Ship Res., 2(3), $52-74$

Granville, P. S. (1978). Similarity-law characterization methods for arbitrary hydrodynamic roughnesses. In P. S. Granville (Ed.), Final Report Naval Ship Research and Development Center, Bethesda, MD. Ship Performance Dept. (pp. 31). Bethesda, MD: David Tayler Naval Ship Research and Development Center.

Granville, P. S. (1987). THREE INDIRECT METHODS FOR THE DRAG CHARACTERIZATION OF ARBITRARILY ROUGH SURFACES ON FLAT PLATES. Journal of Ship Research, 31(No.1), 8 p.

Grigson, C. (1992). Drag losses of new ships caused by hull finish. Journal of Ship Research, 36, 182-196.

Haslbeck, E. G. B. (1992). Microbial biofilm effects on drag-lab and field. Paper presented at the Ship Production Symposium Proceedings.

Hiraga, Y. (1934). Experimental investigations on the resistance of long planks and ships. Zosen Kiokai, 55, 159-199.

Holm, E., Schultz, M., Haslbeck, E., Talbott, W., \& Field, A. (2004). Evaluation of Hydrodynamic Drag on Experimental Fouling-release Surfaces, using Rotating Disks. Biofouling, 20(4-5), 219-226. doi: $10.1080 / 08927010400011245$

ITTC. (2014). General guideline for uncertainty analysis in resistance tests.

KE, S. (1932). Resistance of flat surfaces moving through a fluid. Trans SNAME, 40, 279-313.

Kempf, G. (1937). On the effect of roughness on the resistance of ships. Trans INA, 79, 109-119.

Kim, W. J., Van, S. H., \& Kim, D. H. (2001). Measurement of flows around modern commercial ship models. Experiments in Fluids, 31(5), 567-578. doi: 10.1007/s003480100332

Kiosidou, E. D., Liarokapis, D. E., Tzabiras, G. D., \& Pantelis, D. I. (2017). Experimental Investigation of Roughness Effect on Ship Resistance Using Flat Plate and Model Towing Tests. Journal of Ship Research, 61(2), 75-90. doi: 10.5957/JOSR.61.2.160044 
Larsson, L., Stern, F., \& Visonneau, M. (2013). CFD in Ship Hydrodynamics-Results of the Gothenburg 2010 Workshop. In L. Eça, E. Oñate, J. García-Espinosa, T. Kvamsdal \& P. Bergan (Eds.), MARINE 2011, IV International Conference on Computational Methods in Marine Engineering: Selected Papers (pp. 237-259). Dordrecht: Springer Netherlands.

Lewkowicz, A., \& Das, D. (1986). Turbulent boundary layers on rough surface with and without a pliable overlayer: a simulation of marine fouling. International Shipbuilding Progress, 33, 174-186.

Lewthwaite, J., Molland, A. \& Thomas, K. (1985). An investigation into the variation of ship skin frictional resistance with fouling. Transactions of Royal Institution of Naval Architects, 127, 269-284.

Li, C., Atlar, M., Haroutunian, M., Norman, R., \& Anderson, C. (2019). An investigation into the effects of marine biofilm on the roughness and drag characteristics of surfaces coated with different sized cuprous oxide (Cu2O) particles. Biofouling, 1-19. doi: 10.1080/08927014.2018.1559305

Loeb, G., Laster, D., \& Gracik, T. (1984). The influence of microbial fouling films on hydrodynamic drag of rotating discs. In: J. D. Costlow, R. C. Tipper (Eds.), Marine Biodeterioration: An Interdisciplinary Study, 88-94.

McEntee, W. (1915). Variation of frictional resistance of ships with condition of wetted surface. Trans. Soc. Nav. Arch. Mar. Eng., 24, 37-42.

McEntee, W. (1916). Notes from Model Basin. Transactions of the Society of Naval Architects and Marine Engineers.

Nikuradse, J. (1933). Laws of flow in rough pipes. NACA Technical Memorandum, 1292.

Owen, D., Demirel, Y. K., Oguz, E., Tezdogan, T., \& Incecik, A. (2018). Investigating the effect of biofouling on propeller characteristics using CFD. Ocean Engineering. doi: https://doi.org/10.1016/j.oceaneng.2018.01.087

Schlichting, H. (2017). Boundary-Layer Theory (9th Ed.). Berlin Heidelberg: Springer-Verlag.

Schultz, M. P. (1998). The Effect of Biofilms on Turbulent Boundary Layer Structure. (PhD), Florida Institute of Technology, Melbourne, Florida, US.

Schultz, M. P. (2002). The Relationship Between Frictional Resistance and Roughness for Surfaces Smoothed by Sanding. Journal of Fluids Engineering, 124(2), 492-499. doi: 10.1115/1.1459073

Schultz, M. P. (2004). Frictional Resistance of Antifouling Coating Systems. Journal of Fluids Engineering, 126(6), 1039-1047. doi: 10.1115/1.1845552

Schultz, M. P. (2007). Effects of coating roughness and biofouling on ship resistance and powering. Biofouling, 23(5), 331-341. doi: 10.1080/08927010701461974

Schultz, M. P., Bendick, J. A., Holm, E. R., \& Hertel, W. M. (2011). Economic impact of biofouling on a naval surface ship. Biofouling, 27(1), 87-98. doi: 10.1080/08927014.2010.542809

Schultz, M. P., \& Flack, K. A. (2003). Turbulent Boundary Layers Over Surfaces Smoothed by Sanding. Journal of Fluids Engineering, 125(5), 863-870. doi: 10.1115/1.1598992

Schultz, M. P., \& Myers, A. (2003). Comparison of three roughness function determination methods. Experiments in Fluids, 35(4), 372-379. doi: 10.1007/s00348-003-0686-X

Schultz, M. P., \& Swain, G. W. (1999). The Effect of Biofilms on Turbulent Boundary Layers. Journal of Fluids Engineering, 121(1), 44-51. doi: 10.1115/1.2822009

Schultz, M. P., Walker, J. M., Steppe, C. N., \& Flack, K. A. (2015). Impact of diatomaceous biofilms on the frictional drag of fouling-release coatings. Biofouling, 31(9-10), 759-773. doi: $10.1080 / 08927014.2015 .1108407$

Shapiro, T. A. (2004). The Effect of Surface Roughness on Hydrodynamic Drag and Turbulence: US Naval Academy Annapolis.

Song, S., Demirel, Y. K., \& Atlar, M. (2019a). An investigation into the effect of biofouling on full-scale propeller performance using CFD. Paper presented at the 38th International Conference on Ocean, Offshore \& Arctic Engineering, Glasgow.

Song, S., Demirel, Y. K., \& Atlar, M. (2019b). An investigation into the effect of biofouling on the ship hydrodynamic characteristics using CFD. Ocean Engineering, 175, 122-137. doi: https://doi.org/10.1016/j.oceaneng.2019.01.056

Song, S., Demirel, Y. K., \& Atlar, M. (2020). Penalty of hull and propeller fouling on ship self-propulsion performance. Applied Ocean Research, 94, 102006. doi:https://doi.org/10.1016/j.apor.2019.102006

T. Tezdogan, Y. K. D. (2014). An overview of marine corrosion protection with afocus on cathodic protection and coatings. Brodogradnja, 65, 49-59.

Townsin, R. L. (2003). The Ship Hull Fouling Penalty. Biofouling, 19(sup1), 9-15. doi: $10.1080 / 0892701031000088535$

TQC. (2019). Hull Roughness Gauge. Retrieved 07 May, 2019, from https:/www.tqcsheen.com/en/product/hull-roughness-gauge-en/

Van, S.-H., Ahn, H., Lee, Y.-Y., Kim, C., Hwang, S., Kim, J., . . Park, I.-R. (2011). Resistance characteristics and form factor evaluation for geosim models of KVLCC2 and KCS. Paper presented at the The 2nd 
International Conference on Advanced Model Measurement Technology for the EU Maritime Industry, Newcastle upon Tyne, UK.

Watanabe, S., Nagmatsu, N., Yokoo, K., \& Kawakami, Y. (1969). The augmentation in frictional resistance due to slime. J. Kansai Soc. Nav. Arc., 131(45-51). 